\title{
Earthquake Activities in the Thailand-Laos-Myanmar Border Region: A Statistical Approach
}

\author{
Santi Pailoplee *, Pantarak Channarong, and Vichai Chutakositkanon \\ Earthquake and Tectonic Geology Research Unit (EATGRU), Department of Geology, Faculty of Science, \\ Chulalongkorn University, Bangkok, Thailand
}

Received 20 December 2012, accepted 26 April 2013

\begin{abstract}
A large number of earthquakes have been recorded by instrument in the past along the Thailand-Laos-Myanmar border region. However, the locations of most of these earthquakes do not coincide with the location of morphological features which indicate seismogenic faults. Thus, a statistical evaluation of the earthquake record is focused upon in this earthquake hazard study. The spatial distributions of the $a$ - and $b$-values from the frequency-magnitude distribution relationship were investigated from the complete earthquake catalogue.

Analyses of the possible maximum magnitude earthquakes derived from the $a$ - and $b$-values indicate that the northern part of Mong Pan and the Pak Beng-Luang Prabang areas are capable of generating an earthquake annually with a $m_{\mathrm{b}}$ of 4.0 - 5.0 and that an earthquake of $m_{\mathrm{b}} 7.0$ is possible within 50 years. In addition, with respect to earthquakes with $m_{\mathrm{b}}$ within 4.0 7.0, the calculated short return periods of earthquakes are located in the northern area of Mong Pan (i.e., 1 - 500 years), while the eastern part of Chiang Mai reveals a very long return period up to 5000 years.

With respect to earthquake predictions, the three tested sub-datasets showed a good correlation between a low $b$-value area and the occurrence of a subsequent large earthquake in that region. Thus, based on this effective condition and presentday data, it is possible that a forthcoming earthquake may occur at the northern part of Mong Pan and the Pak Beng-Luang Prabang dams.
\end{abstract}

Key words: Earthquake, Frequency-magnitude distribution, Earthquake catalogue, Thailand-Laos-Myanmar border

Citation: Pailoplee, S., P. Channarong, and V. Chutakositkanon, 2013: Earthquake activities in the Thailand-Laos-Myanmar Border region: A statistical approach. Terr. Atmos. Ocean. Sci., 24, 721-730, doi: 10.3319/TAO.2013.04.26.01(T)

\section{INTRODUCTION}

The Indian-Eurasian plate collision still causes high levels of seismic activity, not only along the Sumatra-Andaman Subduction Zone, but also as widespread intraplate activity where the inland seismogenic faults are dominant (Pailoplee et al. 2009; Fig. 1a). As a result, a large number of hazardous earthquakes are generated continuously, including the latest event of a $\mathrm{M}_{\mathrm{w}} 7.0$ earthquake on March 24th, 2011 (Fig. 1b).

However, due to the complexity in the seismotectonic setting and the blind faults along the intermountain basin of the northern Thailand (Udchachon et al. 2005), the locations of the recorded earthquakes do not normally conform

\footnotetext{
* Corresponding author

E-mail:Pailoplee.S@gmail.com
}

to the defined fault lines. This is especially the case at this study area at the Thailand-Laos-Myanmar borders which encompasses major cities and hydropower dams along the Mekong River (Mekong River Commission 2010; Fig. 1b). Additionally, the steep and forested mountains in this remote borderland are difficult to access for in situ investigation site specific locations of the earthquake sources.

Hence, the alternative approach of using a statistical investigation of recorded earthquakes at a regional scale was emphasized in this study in order to clarify the earthquake activities. The main aims were (i) to estimate the earthquake activities, e.g., possible maximum magnitudes and recurrence intervals of earthquakes, and (ii) locate prospective sources of forthcoming earthquakes along the ThailandLaos-Myanmar border. 


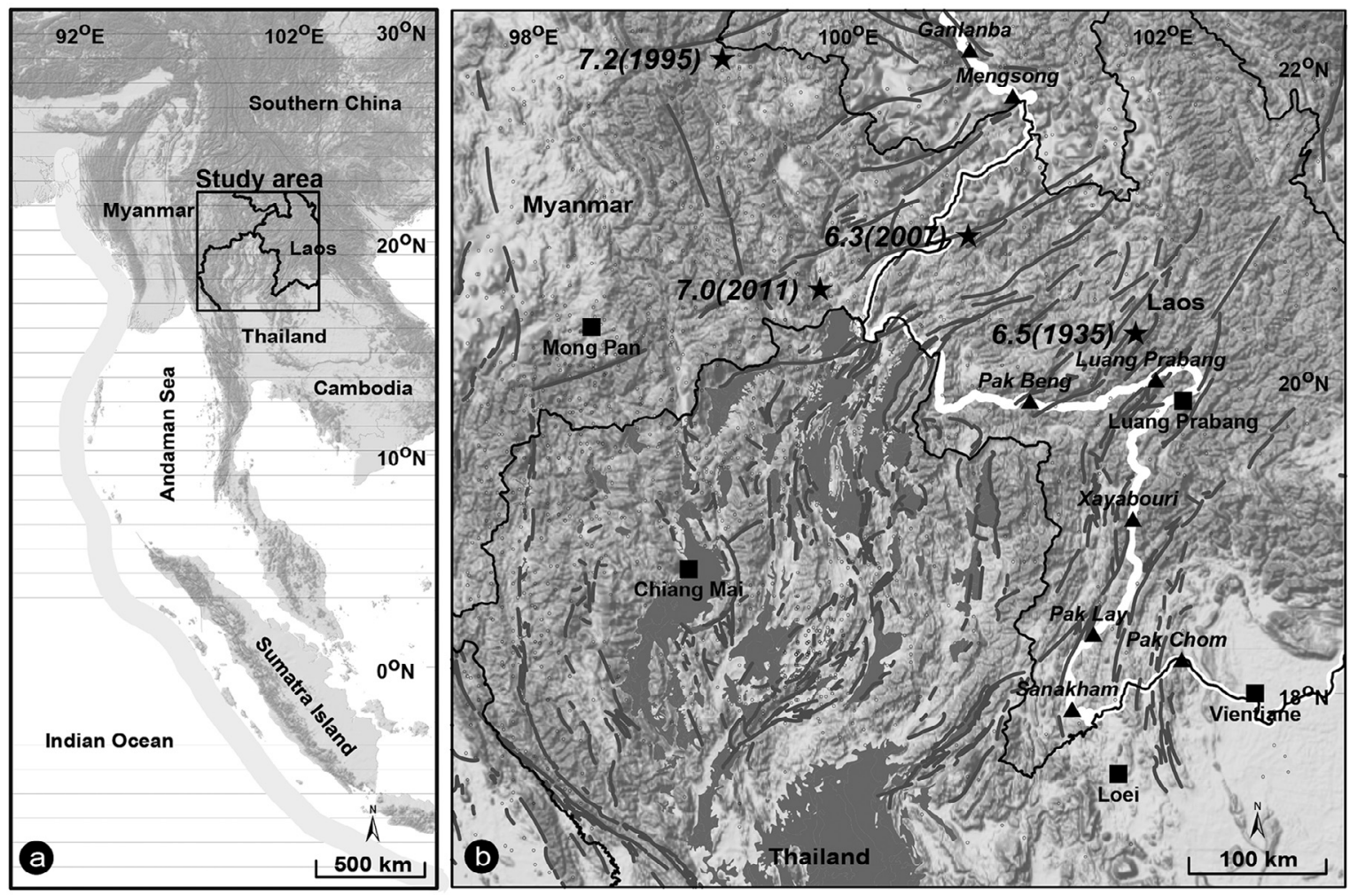

Fig. 1. (a) Map of Mainland Southeast Asia showing the Sumatra-Andaman Subduction Zone (thick grey line) and seismogenic faults, as compiled by Pailoplee et al. (2009) (thin black lines). The study area focuses in the Thailand-Laos-Myanmar border bounded by the square. (b) The study area showing earthquake records after improving the completeness qualitatively (small black circles) and four hazardous earthquakes (black stars). Triangles show the seven proposed dams along the Mekong River mainstream in this region; black squares are the major cities. The grey polygons are the boundary of the intermountain basins as mentioned in the text.

\section{DATA AND COMPLETENESS}

The earthquake catalogues compiled by the Incorporated Research Institutions for Seismology (IRIS), the US National Earthquake Information Center (NEIC), and the Thai Meteorological Department (TMD) were used as the source information for this study. In order to homogenize the magnitude scales, all the other different minor reporting scales $\left(\mathrm{M}_{\mathrm{W}}, \mathrm{M}_{\mathrm{S}}\right.$ and $\left.\mathrm{M}_{\mathrm{L}}\right)$ were converted to $m_{\mathrm{b}}$ (the major reporting scale) following the empirical relationships proposed by Pailoplee et al. (2009). Earthquake declustering (Gardner and Knopoff 1974) was then applied in order to select the main shocks which represent the seismotectonic activities directly. The GENAS algorithm according to Habermann $(1983,1987)$ illustrates the constant rate of the earthquakes with a $m_{\mathrm{b}} \geq 2.8$. Accordingly, earthquake records with a $m_{\mathrm{b}}$ of $<2.8$ were excluded in order to avoid the shift (e.g., Wyss 1991) and stretch (e.g., Zúñiga and Wiemer 1999) of magnitude reporting.

Based on the cumulative numbers of earthquakes against time, as illustrated in Fig. 2a, the earthquake data recorded during 1984 - 2010 were recognized as the most effective. The higher detection rate after 1984 is assumed to be the result of improvement in the network (Zúñiga and Wiemer 1999). Therefore, the composite earthquake catalogue of main shocks with a $m_{\mathrm{b}} \geq 2.8$ during 1984 - 2010 was defined as the complete earthquake catalogue and was used for this qualitative investigation of the earthquake activities. This was comprised of 920 such main shocks.

\section{EARTHQUAKE ACTIVITIES}

Based mainly on the frequency-magnitude earthquake distribution (FMD) (Ishimoto and Iida 1939; Gutenberg and Richter 1944), the empirical relationship between the average number of earthquakes per year $(N)$ with a magnitude equal to or larger than $M$ is expressed in Eq. (1);

$\log (N)=a-b M \quad$ or $\ln (N)=\ln \alpha-\beta M$

Within Eq. (1), $a$ and $b$ are positive, real constants. The $a$-value implies the entire seismicity rate or the annual number of earthquakes above the Richter magnitude 0 or whereas $b$-value represents the ratio of the occurrence of small to large earthquakes. Meanwhile, the parameters $\alpha$ and $\beta$ are 

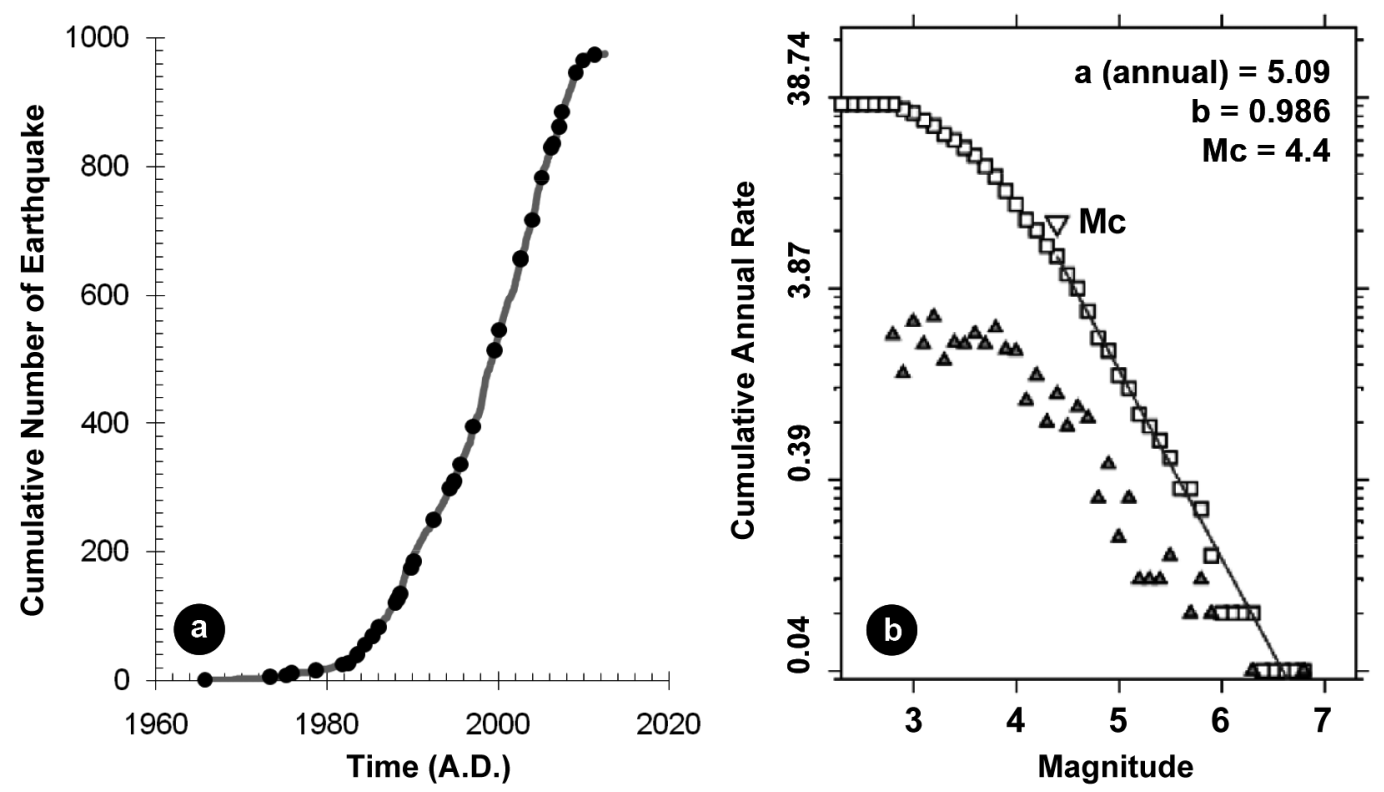

Fig. 2. (a) Cumulative number of earthquakes with a $m_{\mathrm{b}} \geq 2.8$ (grey line) showing the different rates of seismicity reported during the years 1964 - 2012. The black circles are earthquakes with a $m_{\mathrm{b}}$ of $\geq 5$.0. (b) FMD plot of the seismicity data recorded $m_{\mathrm{b}} \geq 2.8$ during $1984-2010$. Triangles indicate the number of earthquakes of each magnitude; squares represent the cumulative number of earthquakes equal to or larger than each magnitude. Solid lines are the lines of best fit according to Woessner and Wiemer (2005). Mc is defined as the magnitude of completeness.

related to $a$ and $b$ by Eqs. (2a) and (2b), respectively;

$\alpha=\exp [a \ln (10)]$

and

$\beta=b \ln (10)$

For earthquake activity investigations, initially we examined the FMD of the entire selected earthquake data (i.e., $m_{\mathrm{b}} \geq 2.8$ recorded during $1984-2010$ ), and estimated the magnitude of completeness (Mc) which represents the magnitude level of the complete report. Figure $2 b$ illustrates the FMD plot from which $a$ - and $b$-values are estimated 5.1 and 1.0 , respectively. Using the entire-magnitude-range method (Woessner and Wiemer 2005), the estimated Mc is approximately $4.4 \mathrm{mb}_{\mathrm{b}}$.

To assess the earthquake activities spatially, the study area was gridded with a $0.1^{\circ} \times 0.1^{\circ}$ spacing. After iterative tests, all the earthquake events from the selected catalogue (the 920 main shock events detailed above) within a fixed $100-\mathrm{km}$ radius from each individual grid node were selected. The $a$ - and $b$-values including the other statistically significant values were then calculated using the ZMAP program (Wiemer 2001) and spatially mapped (Fig. 3). The FMD plots for some specific areas are prepared as shown in Fig. 4. However, for the areas of Pak Lay, Pak Chom, and Sanakham Dams, we could not make the FMD due to statistic insufficiency of the earthquake data. For instance in Fig. 4, the $a$-values are estimated 4.9 and 2.0 at the Mong Pan and Pak Beng Dam, respectively. These imply that the entire seismicity rate of the Mon Pan area is higher than the rate around the Pak Beng Dam. In addition, the various Mc (i.e., 2.8 - 4.2) obtained from the FMD plots indicates the difference of the detection capability of the existing seismic recording networks.

Based on Figs. 3a and b, the spatial variations of the $a$ and $b$-values were almost coincident and showed two obvious regions of low $a$ - and $b$-values at the (i) the eastern and southern parts of Mong Pan in Myanmar and the (ii) Pak Beng and Luang Prabang dams in Laos. Viewed seismotectonically, comparatively low $a$ - and $b$-values represent a low entire earthquake activity and a low ratio of small-size earthquakes to large-size earthquakes, respectively. The standard deviation and the goodness of fit of the FMD (Figs. $3 \mathrm{c}$ and d) reveal that the obtained $a$ - and $b$-values are likely to be reliable with low variations.

\subsection{Possible Maximum Magnitude}

Based on Yadav et al. (2011), various values representing the earthquake activities can be calculated using the $\alpha$ and $\beta$ values from the FMD. For instance, the possible maximum magnitude in $t$ year of interest $u_{t}$ can be estimated as shown in Eq. (3); 
$u_{t}=\frac{\ln (\alpha t)}{\beta}$

For example, $u_{1}[=\ln (\alpha) / \beta]$ is the maximum earthquake which is capable of occurring annually, meanwhile $u_{5}$ reflects the possible maximum magnitude which might occur on an average of in every 5 years, respectively.

Thus, the obtained $a$ - and $b$-values of a individual node (Fig. 3) are converted systematically to their corresponding $\alpha$ - and $\beta$-values according to the relationships mentioned in Eqs. (2a) and (2b). The possible maximum magnitude in $1,5,10$ and 50 years was then calculated and mapped (Fig. 5).

The results indicate that the northeastern part of Mong Pan and the area of Pak Beng and Luang Prabang dams are capable of generating an earthquake with a larger magnitude than that of the other regions, with a potential annual magnitude of around $m_{\mathrm{b}} 4.0-5.0$ and an earthquake with a magnitude up to $m_{\mathrm{b}} 7.0$ within 50 years (Fig. 5).
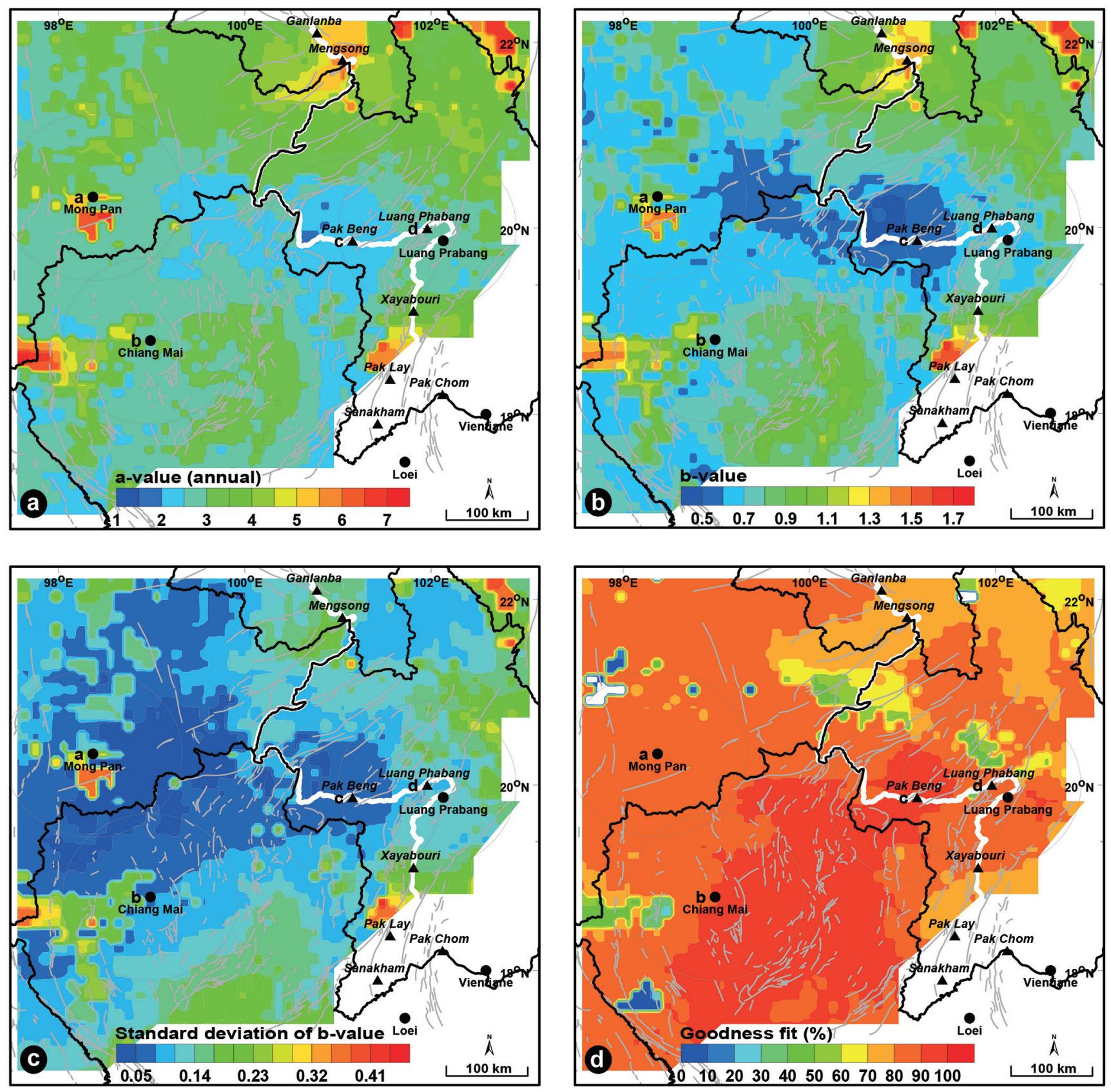

Fig. 3. Spatial distributions of the (a) $a$-value, (b) $b$-value, (c) standard deviation of each obtained $b$-value, and (d) the goodness fit of the FMD. The circles illustrate the 100-km radius from 4 specific areas, i.e., a - d, where the FMD plots are demonstrated in Fig. 4. 


\subsection{Return Period of Earthquake}

The earthquake return period in the unit of year of individual magnitude $M\left(T_{M}\right)$, which an inverse value of cumulative number of earthquakes that equal to and larger than $(M)$, was evaluated as in Eq. (4) (Yadav et al. 2011) based on the seismicity parameters $\alpha$ and $\beta$ in this study.

$T_{M}=\frac{\exp (\beta M)}{\alpha}$
The results reveal that the northern part of the study area, covering Mong Pan, Pak Beng, and Luang Prabang dams, has a potential to generate an earthquake within a short period. For instance, the return periods of the earthquake with $m_{\mathrm{b}}$ of 4, 5, 6 and 7 were 1, 5, 50 and 500 years, respectively (Fig. 6). In contrast, for the eastern part of Chiang Mai, the average time intervals of the earthquake occurrences were around $5-5000$ years for an earthquake magnitude of $4-7 m_{\mathrm{b}}$ (Fig. 6).
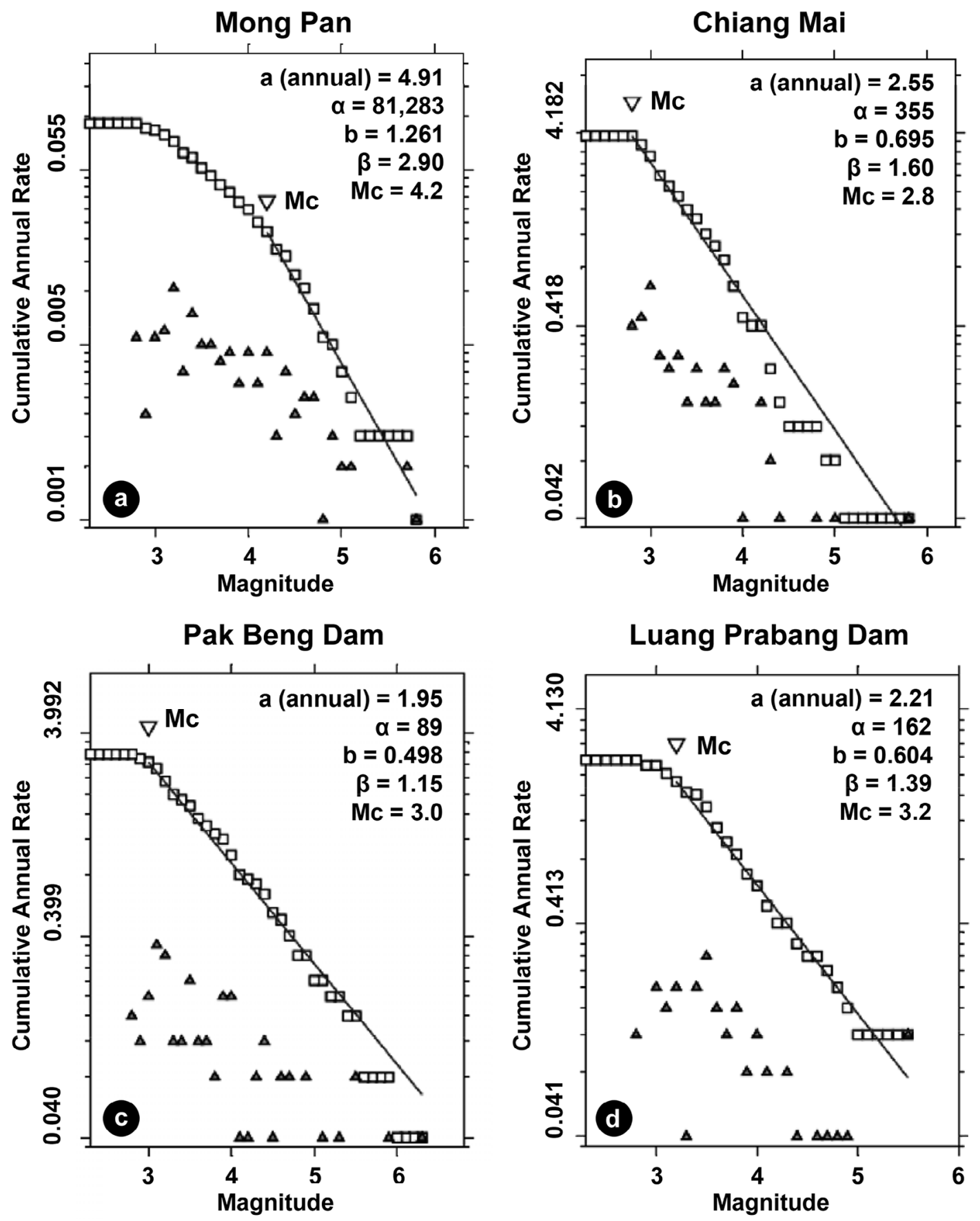

Fig. 4. The FMD plot of the seismicity data located within the 100-km radius from 4 demonstrated areas as mentioned in Fig. 3. 


\section{PROSPECTIVE EARTHQUAKE SOURCE}

With regard to earthquake prediction, Scholz (1968) and Wyss (1973) proposed that the inverse correlation between the amount of stress accumulated in the hypocentral area and the $b$-value was effective for earthquake forecasting. Many studies have since shown a good correlation between a low $b$-value area and the subsequent existence of an earthquake (e.g., Schorlemmer et al. 2003; Nuannin et al. 2005; Chan et al. 2012). However, in order to locate future earthquakes, unlike the method described in section
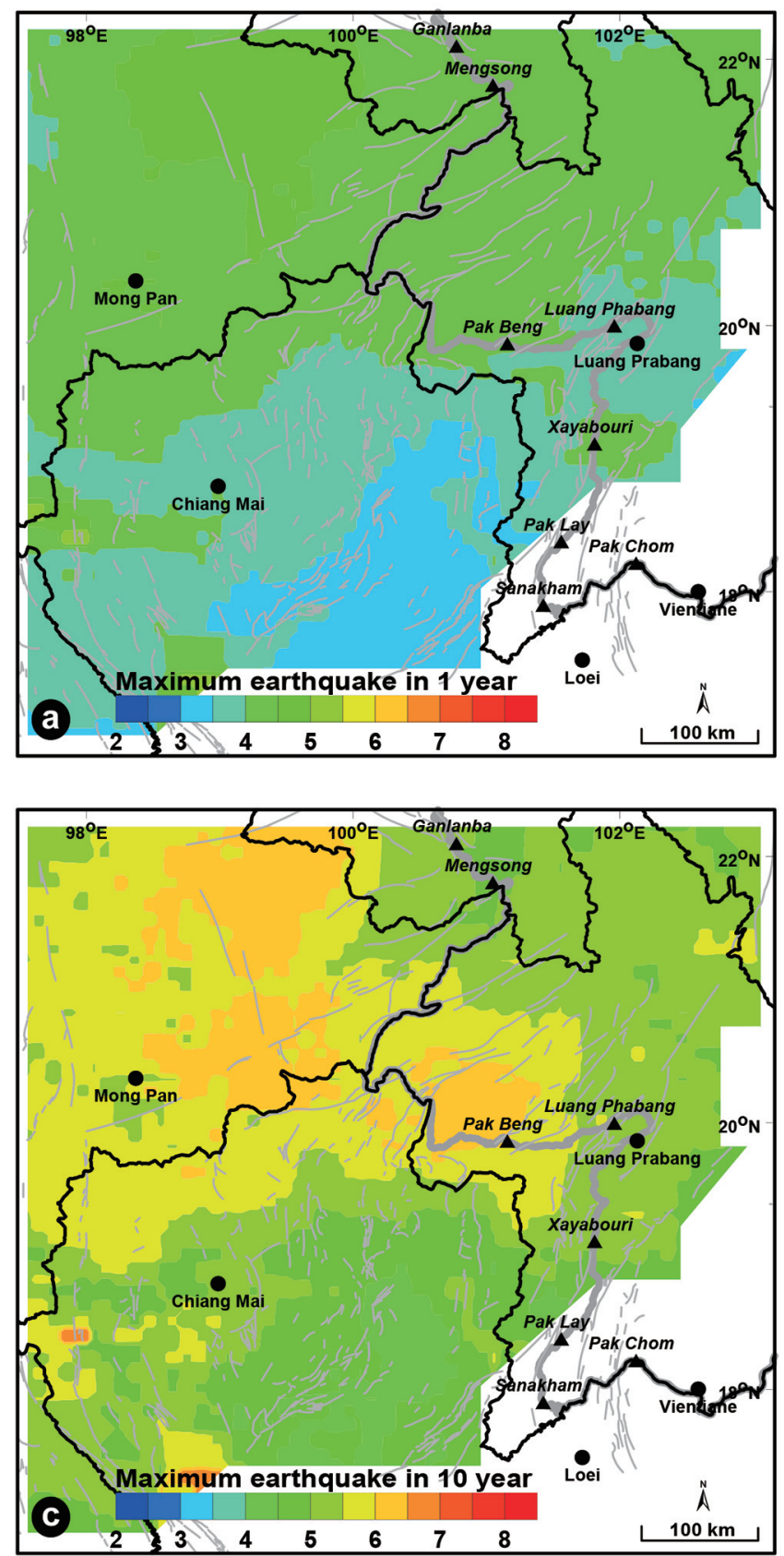

3 above, the characteristics of the $b$-values were evaluated differently.

Here, to locate future earthquakes, the $b$-values derived from Eq. (1) were analyzed according to the assumption proposed by Nuannin et al. (2005). In each individual $0.1^{\circ} \times$ $0.1^{\circ}$ grid node, the 50 earthquake events closest to the grid node were selected to evaluate the local $b$-value.

In order to test the applied assumption, three sub-datasets each of a different recording time span (1984 - 1995, 1984 - 2000 and 1984 - 2005) were used to separately investigate the spatial distribution of $b$-values and subsequent
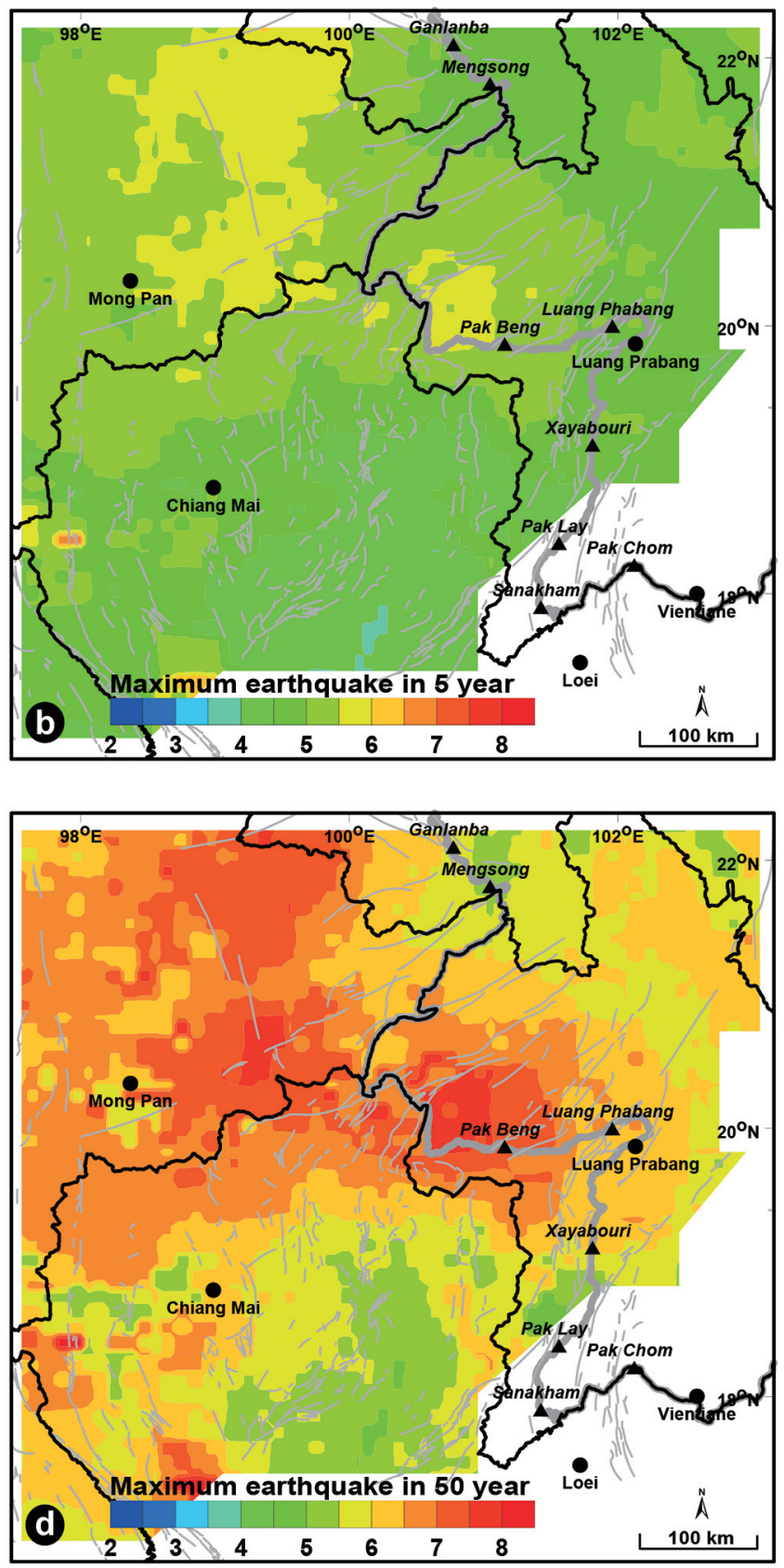

Fig. 5. Maximum earthquake magnitude likely to be generated in the individual time span of the next (a) 1, (b) 5, (c) 10, and (d) 50 years. 
earthquake events. The good consistency found between the areas showing a low $b$-value and the occurrence of a subsequent earthquake with a $m_{\mathrm{b}} \geq 5.0$ in individual area support that the assumption of Nuannin et al. (2005) was valid in locating prospective future earthquake sources from these derived $b$-values (Figs. 7a - c). Hence, the present-day dataset of 1984 - 2010 was analyzed to locate the current local $b$-values and these were then spatially mapped (Fig. 7d).

Based on the present-day $b$-value distribution, comparatively low $b$-value areas were found to be located in (i) the northern part of Mong Pan, eastern Myanmar and (ii) the
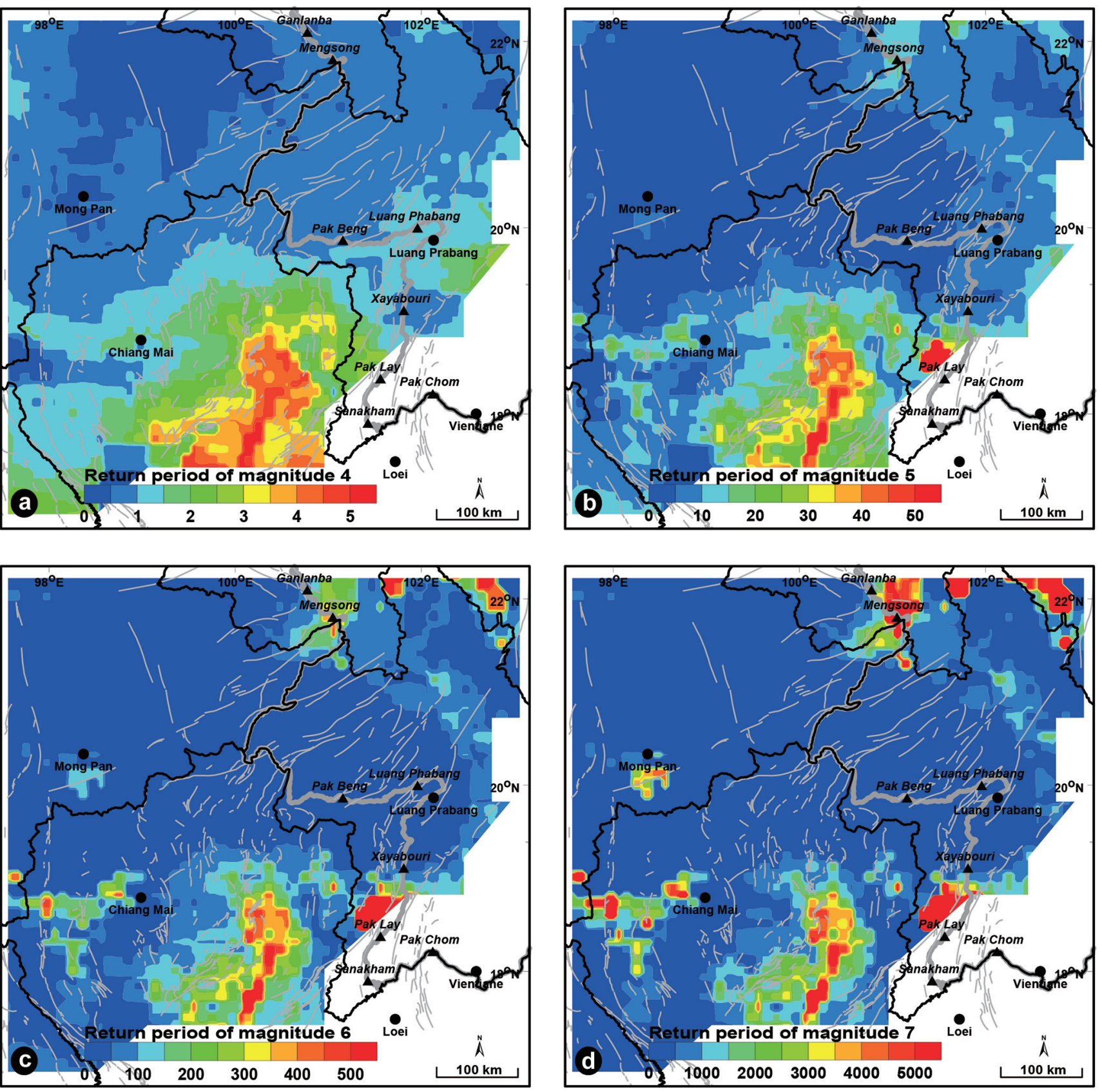

Pak Beng and Luang Prabang dams in Laos $(b=\sim 0.5-0.6)$. The latest $m_{\mathrm{b}} 7.0$ earthquake, which occurred in March 24, 2011, was also located within a low $b$-value area (Fig. 7d). Thus, for the likely location of future earthquakes both of these two low $b$-value regions are strong candidates, and especially the area of Pak Beng-Luang Prabang where some of the Mekong River meg $a$-schemes of dams are proposed.

\section{DISCUSSION AND CONCLUSION}

In this study, present-day earthquake activities were

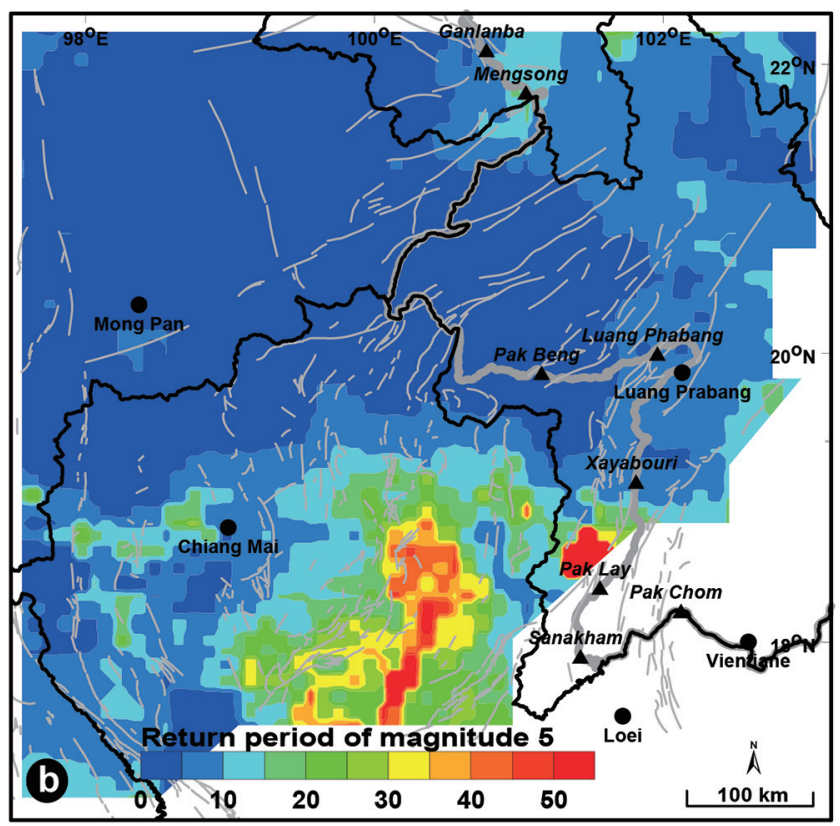

Fig. 6. The return periods of earthquakes for those at a $m_{\mathrm{b}}$ level of (a) 4, (b) 5 , (c) 6 , and (d) 7 . 
investigated statistically along the intraplate of the Thailand-Laos-Myanmar border. After qualitatively improving the earthquake catalogue, the spatial variation of $a$ - and $b$ values according to the FMD were analyzed and mapped. Then, the earthquake parameters representing the potential earthquake hazard situation were evaluated in the study area based mainly on the obtained $a$ - and $b$-values.

For the most probable largest earthquake magnitude in a given time period, the results indicate that the northern part of Mong Pan and the area of Pak Beng and Luang
Prabang dams are capable of generating an earthquake annually with a $m_{\mathrm{b}}$ of $4.0-5.0$, whilst in a 50-year period a $m_{\mathrm{b}} 7.0$ earthquake can likely be generated. In addition, the expected occurrence time intervals of earthquakes with a $m_{\mathrm{b}}$ of 4, 5, 6 and 7 were 1, 5, 50 and 500 years, respectively.

For prediction of future earthquakes, the spatial distribution of the $b$-values was investigated according to the assumption proposed by Nuannin et al. (2005). The comparatively low $b$-value areas calculated from the three subdatasets support the spatial relationship between a low $b$ -
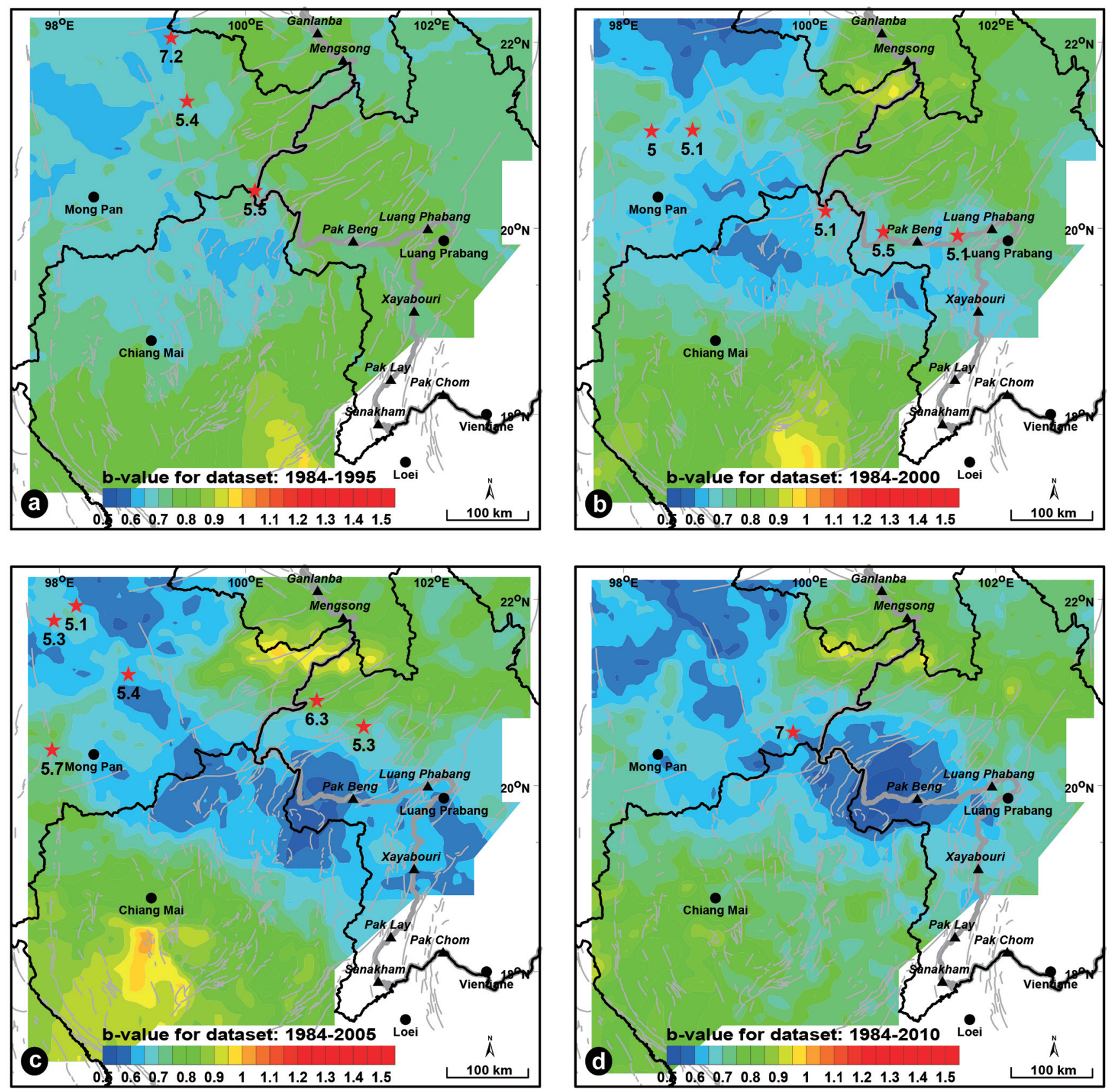

Fig. 7. Spatial $b$-value distributions, as derived using the seismicity data recorded during (a) 1984 - 1995, (b) 1984 - 2000, (c) 1984 - 2005, and (d) 1984 - 2010. Red stars indicate earthquakes with a $m_{\mathrm{b}} \geq 5.0$ that were generated after the seismicity data used. 
value and the occurrence of a subsequent earthquake in that area. Accordingly, the results obtained from the present-day dataset should then be reasonably reliable, and suggested prospective future earthquake sources at (i) the northern part of Mong Pan, Myanmar, and (ii) the Pak Beng and Luang Prabang dams, northern Laos.

Although this study is an important step in arousing public awareness about earthquake activities in this remote area, some errors from the non-linear relationship of earthquake characteristics (Youngs and Coppersmith 1985) are also possible. Moreover, according to Wells and Coppersmith (1994), the possible maximum magnitude depends directly on the fault size, such as the rupture length, area, or displacement. Thus, the results obtained from a linear extrapolation may overestimate the limit of the possible subsequent earthquake magnitude. Therefore, the results presented in this study should be interpreted carefully, or confirmed by alternative means, for the design of critical earthquake resistant infrastructures. To this end, to further refine the accuracy, more paleoseismological studies are indispensable.

Acknowledgements This work was jointly sponsored by the Integrated Innovation Academic Center (IIAC): Chulalongkorn University Centenary Academic Development Project (CU56-CC04), the Higher Education Promotion and National Research University Project of Thailand, Office of the Higher Education Commission (CC508B-56), and The Thai Government Stimulus Package 2 (TKK:2555; PERFECTA). Thanks are also extended to T. Pailoplee for the preparation of this manuscript. We thank the Publication Counseling Unit (PCU), Faculty of Science, Chulalongkorn University, for a critical review and improved English. We acknowledge the thoughtful comments and suggestions by Yih-Min Wu (Editor), Mei-Ling Chen (Assistant Editor), Yuichi Sugiyama, and Chung-Han Chan who enhanced the quality of this manuscript significantly.

\section{REFERENCES}

Chan, C. H., Y. M. Wu, T. L. Tseng, T. L. Lin, and C. C. Chen, 2012: Spatial and temporal evolution of $b$-values before large earthquakes in Taiwan. Tectonophysics, 532-535, 215-222, doi: 10.1016/j.tecto.2012.02.004. [Link]

Gardner, J. K. and L. Knopoff, 1974: Is the sequence of earthquakes in Southern California, with aftershocks removed, Poissonian? Bull. Seismol. Soc. Am., 64, 1363-1367.

Gutenberg, B. and C. F. Richter, 1944: Frequency of earthquakes in California. Bull. Seismol. Soc. Am., 34, 185188.

Habermann, R. E., 1983: Teleseismic detection in the Aleutian Island Arc. J. Geophys. Res., 88, 5056-5064, doi:
10.1029/JB088iB06p05056. [Link]

Habermann, R. E., 1987: Man-made changes of Seismicity rates. Bull. Seismol. Soc. Am., 77, 141-159.

Ishimoto M. and K. Iida, 1939: Observations of earthquakes registered with the microseismograph constructed recently. Bull. Earthq. Res. Inst., Univ. Tokyo, 17, 443478.

Mekong River Commission, 2010: State of the basin report 2010. Mekong River Commission, Vientiane, Lao PDR.

Nuannin, P., O. Kulhanek, and L. Persson, 2005: Spatial and temporal $b$ value anomalies preceding the devastating off coast of NW Sumatra earthquake of December 26, 2004. Geophys. Res. Lett., 32, L11307, doi: 10.1029/2005GL022679. [Link]

Pailoplee, S., Y. Sugiyama, and P. Charusiri, 2009: Deterministic and probabilistic seismic hazard analyses in Thailand and adjacent areas using active fault data. Earth Planets Space, 61, 1313-1325.

Scholz, C. H., 1968: The frequency-magnitude relation of microfracturing in rock and its relation to earthquakes. Bull. Seismol. Soc. Am., 58, 399-415.

Schorlemmer, D., G. Neri, S. Wiemer, and A. Mostaccio, 2003: Stability and significance tests for $b$-value anomalies: Example from the Tyrrhenian Sea. Geophys. Res. Lett., 30, SDE 3-1-SDE 3-4, doi: 10.1029/20 03GL017335. [Link]

Udchachon, M., P. Charusiri, V. Daorerk, K. Won-in, and I. Takashima, 2005: Paleo-earthquake studies along the southern portion of Phrae basin, northern Thailand. Proceedings of the International Conference of Geology, Geotechnology, and Mineral Resources of Indochina, Khon Kaen, Thailand, 511-516.

Wells, D. L. and K. J. Coppersmith, 1994: New empirical relationships among magnitude, rupture length, rupture width, rupture area, and surface displacement. Bull. Seismol. Soc. Am., 84, 974-1002.

Wiemer, S., 2001: A software package to analyze seismicity: ZMAP. Seismol. Res., 72, 373-382, doi: 10.1785/ gssrl.72.3.373. [Link]

Woessner, J. and S. Wiemer 2005: Assessing the Quality of earthquake catalogues: Estimating the magnitude of completeness and its uncertainty. Bull. Seismol. Soc. Am., 95, 684-698, doi: 10.1785/0120040007. [Link]

Wyss, M., 1973: Towards a physical understanding of the earthquake frequency distribution. Geophys. J. Int., 31, 341-359, doi: 10.1111/j.1365-246X.1973.tb06506. x. [Link]

Wyss, M., 1991: Reporting history of the central Aleutians seismograph network and the quiescence preceding the 1986 Andreanof Island earthquake. Bull. Seismol. Soc. Am., 81, 1231-1254.

Yadav, R. B. S., J. N. Tripathi, D. Shanker, B. K. Rastogi, 
M. C. Das, and V. Kumar, 2011: Probabilities for the occurrences of medium to large earthquakes in northeast India and adjoining region. Nat. Hazards, 56, 145167, doi: 10.1007/s11069-010-9557-y. [Link]

Youngs, R. R. and K. J. Coppersmith, 1985: Implications of fault slip rates and earthquake recurrence models to probabilistic seismic hazard estimates. Bull. Seismol. Soc. Am., 75, 939-964.

Zúñiga, F. R. and S. Wiemer, 1999: Seismicity patterns: are they always related to natural causes? Pure Appl. Geophys., 155, 713-726, doi: 10.1007/s000240050285. [Link] 